\title{
Exploring loneliness and students' sense of coherence (S-SoC) in the university setting
}

\author{
Andrea Limarutti ${ }^{1,2}$ (D) $\cdot$ Marco Johannes Maier ${ }^{3} \cdot$ Eva Mir $^{1}$
}

Accepted: 17 June 2021

(C) The Author(s) 2021

\begin{abstract}
Background. Loneliness is a prevalent global public health issue, and this topic is also common among university students. From a health-related, resource-oriented approach like the salutogenic model, loneliness can be interpreted as a potential stressor. To cope effectively with this stressor, a strong Sense of Coherence is needed to mobilize resources like social support. Interventions to promote health and wellbeing within a university setting should include a salutogenic focus. However, currently, research regarding salutogenesis within the higher education setting is lacking. Therefore, this study aims to make the first attempt to explore the relation between loneliness and the Students' Sense of Coherence (S-SoC) among university students. Methods. An online questionnaire was sent out to all university students from the Carinthia University of Applied Sciences (CUAS), Austria. The online questionnaire was completed by 584 students (response rate of $28.86 \%$ ); $67.3 \%$ were female, and the average age was 25.16 years ( $\mathrm{SD}=6.27$ years). Full-time students made up $75.6 \%$ of the sample, and $84.6 \%$ were in a Bachelor's degree program. The S-SoC and the sub-scales comprehensibility, meaningfulness and manageability were measured by using the valid S-SoC scale (Brunner et al., 2009). Social and emotional loneliness was measured by using the six-item De Jong Gierveld loneliness scale (Jong Gierveld \& van Tilburg, 2006). Spearman correlations and Kruskal-Wallis H-tests were computed among all loneliness and S-SoC sub-scales and other variables (e.g., age, sex...). Furthermore, a graphical model was used to show structural relationships between loneliness and S-SoC and control variables. Results. The results showed that students feeling moderate or severe general loneliness had lower S-SoC scores than students feeling low or not general lonely. Manageability was a pivotal point in this model, as it was inversely proportional to both measures of loneliness. Perceived social loneliness was reported most by men and part-time students. Conclusion. In order to fulfill study-related demands, students activate appropriate resources (e.g., social support), which corresponds to low social and emotional loneliness. However, in the development of health promoting interventions against loneliness among students, it would be necessary to consider sex and mode of study and to address health needs and problems with a salutogenic focus.
\end{abstract}

Keywords Loneliness · Students' sense of coherence $\cdot$ Manageability $\cdot$ Graphical models $\cdot$ Setting specific health promotion . Salutogenesis

\section{Introduction}

Loneliness is a prevalent global public health issue, and surveys in Europe and the USA estimate the prevalence of

Andrea Limarutti

a.limarutti@fh-kaernten.at

1 Department of Health Sciences and Social Work, Carinthia University of Applied Sciences, Spittal, Austria

2 Department of Human Sciences, University of Education Schwäbisch Gmünd, Schwäbisch Gmünd, Germany

3 Independent Researcher, Vienna, Austria loneliness among the elderly at between 5\% and $43 \%$ (Leigh-Hunt et al., 2017). Loneliness is often assumed to affect older people merely; however, it is also spread among young adults (Qualter et al., 2015; Victor \& Yang, 2012) and can occur over the whole lifespan. Victor and Yang (2012) analyzed patterns of loneliness in adults (aged $>15$ years) based on data from the European Social Survey, concluding that about $21 \%$ of people between 20 and 34 years felt lonely. In a US study among 4885 individuals aged 10 97 years, Shovestul et al. (2020) found age to be associated with loneliness, with a peak in individuals aged 18.6 years (95\% CI $[16.7,20.6])$. There is no substantial evidence for gender differences in loneliness and suggested that mean levels of loneliness across the lifespan are similar for males 
and females. However, significant gender differences in loneliness with minimal effects for children, adolescents and young adults, suggesting that males are slightly lonelier than females, were found (Maes et al., 2019).

Loneliness can be defined as "(...) the unpleasant experience that occurs when a person's network of social relationships is deficient in some important way, either quantitatively or qualitatively" (Perlman \& Peplau, 1981). Furthermore, Weiss (1973) differs between social and emotional loneliness. Social loneliness means the absence of broader group contacts or an engaging social network that offers people the feeling they can trust in consisting of friends or colleagues. Emotional loneliness can be described as the absence of an intimate individual and a close emotional attachment and may include feelings of emptiness, abandonment, and/or feelings of loss (de Jong Gierveld \& van Tilburg, 2010).

Various studies have linked loneliness to psychological problems such as depression, psychological stress or anxiety (Campagne, 2019; Matthews et al., 2019; Mushtaq et al., 2014; Richard et al., 2017) and sleep disturbance (Griffin et al., 2020). Additionally, loneliness is associated with cardiovascular problems (Petitte et al., 2015) and overall morbidity and mortality (Schinka et al., 2012; Yanguas et al., 2018). For instance, in university students, loneliness is positively associated with feelings of depression and anxiety (Diehl et al., 2018), intensive media use (Aalbers et al., 2019), difficulty initiating and maintaining sleep (Hayley et al., 2017) or a higher risk of academic failure (Stadtfeld et al., 2019). Thus, loneliness is found to be a key risk factor in a range of negative health outcomes and may lead to poor health conditions (Tzouvara et al., 2015).

In health promotion, the salutogenic model by Aaron Antonovsky (Antonovsky, 1979) is often used as a theoretical framework to explain the question of effective factors for the maintenance of health and overcome health risks and stressors. The salutogenic model uses a health-related, resource-oriented approach (Bengel et al., 2009). Stressors are the start of the stress process and can be differentiated on a biochemical level (e.g., bacterium, viruses...) and on a psychosocial level (e.g., constant strains, daily hassles or critical personal experiences). The confrontation with stressors brings people into a state of psychological and physical tension. Suppose the individual succeeds in managing the state of tension, the individual moves into the positive direction on the health continuum. If the coping is not successful, physical and psychological stress reactions may arise and may lead to disease (Faltermaier, 2018). In this study, loneliness can be defined as a potential stressor, which needs to be managed. When it comes to coping effectively with stressors, Generalized Resistance Resources (GRRs) are needed. For example, GGRs may include factors like material resources, knowledge and intelligence, coping strategies and social support (Idan et al., 2017). Social support is often seen as a resource for people's mental and physiological health and well- being (Wrzus et al., 2013); it can protect individuals from maladjustment and influence the accomplishment of life tasks (Saldarriaga et al., 2015). Social support can be given by family, romantic relations and friends (Lee \& Goldstein, 2016). Friendships can be seen as relations with reciprocally received support (Wrzus et al., 2017) with a health-promoting effect (Holt-Lunstand, 2017). According to McIntyre et al. (2018), university friendship groups are the most effective tool for preventing distress in university students.

Another acknowledged resource for people's health and well-being is the Sense of Coherence (SoC), the core element of the salutogenic model by Aaron Antonovsky (Antonovsky, 1979). The SoC is a result of life experiences and consists of three dimensions (Koelen et al., 2017): (1) Comprehensibility is the cognitive dimension of the $\mathrm{SoC}$ and refers to the cognitive control of the environment; stimuli are predictable, ordered and explicit. (2) The second dimension, meaningfulness, is the motivational component and relates to the feeling that life makes sense, and situations are assessed as challenges and have to be coped with. (3) The third dimension, manageability, is the behavioral component and includes the extent of personal coping resources, the ability to reflect internal and external resources, to identify and mobilize them to enhance effective coping in a health promoting way. However, manageability means having own resources and competencies and the belief that other people or a higher power can help overcome difficulties (Bengel et al., 2009).

So, people who score highly in all three dimensions have a strong SoC, which is helpful to activate appropriate resources for specific circumstances. Furthermore, a strong SoC is assumed to promote more excellent health and well-being (Eriksson \& Lindström, 2006; Feldt et al., 2003; Koelen et al., 2017; Shankland et al., 2019), and more efficient recovery of stressful situations (Lundberg \& Toivanen, 2019). Nevertheless, adverse life circumstances, such as lack of social support, may inhibit the ideal development of SoC (Bengel et al., 2009). The SoC was originally defined as a global orientation towards life, but it has since been discussed in a setting specific context. Specifying the SoC for a given setting, such as universities, allows one to study particularly relevant relationships within the respective context so that different setting specific interventions can be developed (Bauer, 2017). For the university setting, the University SoC (U-SoC) was developed to measure comprehensibility, meaningfulness and manageability among university staff (Gräser, 2003), and Brunner et al. (2009) developed the Students' Sense of Coherence scale (SSoC) following Gräser's U-SoC measures.

To sum up, from a health-related and resource-oriented approach, a strong SoC to mobilize GGRs, like social support, is needed to cope effectively with stressors like loneliness to promote individuals' health (Mittelmark \& Bauer, 2017).

To date, much research about students' health was published, but focusing on descriptive psychosomatic complaints 
(Bruffaerts et al., 2018; Eissler et al., 2020; Ibrahim et al., 2013). So far, in the field of students' health, the relation between resources and stressors, in the context of the salutogenic model, research is missing, and few studies address the relationship between SOC and social support (Bengel et al., 2009; Dooris et al., 2017). For example, studies among children and adolescents found out that social support perceived from classmates, teachers, friends or peers contributes to an individual's level of SoC and social support (Idan et al., 2017). Thus, only limited research explores the link between social support and SoC (e.g., Heiman, 2004). Heiman (2004) suggests when focusing on students, and their interaction with the environment, concepts of stress, coping and social support should be used as inseparable characteristics. The current study contributes to promoting such questions within the university context and follows the suggestion of Heiman (2004). Another characteristic of this study is the differentiated classification of loneliness and investigation of the absence of broader group contacts or an engaging social network (social loneliness) and the feeling of emptiness, abandonment and/or of loss, respectively the absence of an intimate or close emotional attachment (emotional loneliness). Maes et al. (2019) pointed out that research examining different types of loneliness more systematically is missing.

To the best of the author's knowledge, research investigating the SoC setting specifically with social and emotional loneliness as a stressor among university students, is still missing. Currently, research regarding salutogenesis within the higher education setting is lacking (Dooris et al., 2017). Therefore, this current study aims to make the first attempt to explore the relation between loneliness and the S-SoC among university students. This study contributes to the statement of Dooris et al. (2017) and explores negative factors in combination with resources. Furthermore, it follows the suggestion to examine types of loneliness more systematically. In the subsequent exploratory analyses, the variables sex, field of study, mode of study and intended degree, age and number of friendlike relationships at the CUAS were additionally included. Therefore, instead of preconceived hypotheses, in this exploration, aspects such as:

- Are there associations between loneliness and the S-SoC?

- Is there a difference between emotionally/socially lonely and not lonely students with regard to S-SoC, sex, mode of study, age, field of study, intended degree and number of friend-like relationships at CUAS?

- How does emotional and social loneliness relate to the sub-scales of the S-SoC (comprehensibility, meaningfulness and manageability)?

- What is the structural relationship between loneliness, SSoC, sociodemographic and study-related variables? were investigated.

\section{Methods}

\section{Study Sample}

The analysis is based on data from a need assessment survey, open to all CUAS-students, which was carried out between 28th March 2019 and 31st May 2019. As the online questionnaire was provided in German, only students who understood German could fill in the questionnaire. Different recruitment strategies were used to reach as many students as possible (e.g., distributing flyers, sharing the study in social networks, and mailing lists). Students were informed about the study's aims, and data security and that participation were voluntary. By selecting the "agreement button" before starting the survey, each participant gave informed consent. The online questionnaire was completed by 584 students, which amounts to a response rate of $28.86 \%$ of all CUAS-students $(N=2023$ in summer term 2019); $67.3 \%$ were female students. On average, participants were 25.16 years $(S D=6.27$ years $)$ old. Full-time students made up $75.6 \%$ of the sample, and $84.6 \%$ were in a Bachelor degree program. The majority $(46.7 \%)$ of students could be assigned to the field of study Health and Social Work. The field of study Management included $21.6 \%$ of the participants, $20.9 \%$ of the participating students belonged to the field of study Engineering and IT, and 10.9\% belonged to Civil Engineering and Architecture. The number of friendlike relationships at CUAS ranged between 0 and $100(M d n=$ 5; $M=7.64)$. The Medical Ethics Committee of Carinthia approved the study and the whole KukiS-Toolbox project (EK Nr. A30/19).

\section{Measures}

All measures and items were selected setting-specifically to the university context.

Students' Sense of Coherence (S-SoC). Using the 12-item, reliable (Cronbach's alpha $=.73$ according to Brunner et al., 2009; for this sample Cronbach's alpha $=.838$ ) and valid SSoC Scale (Brunner et al., 2009), the overall S-SoC and its sub-scales comprehensibility (4 items, e.g., "For me, the Carinthia University of Applied Sciences has clear and transparent structures."), meaningfulness (5 items, e.g., "I have the feeling that the Carinthia University of Applied Sciences is an enrichment for my life.") and manageability (3 items, e.g., "Whenever I am faced with a difficult problem at Carinthia University of Applied Sciences, I find people who help to solve my problem.") were measured. Brunner et al. (2009) did not calculate Cronbach's alpha for the sub-scales. For this sample, the Cronbach's alpha for the sub-scales was between .51 and .75 (meaningfulness $=.51$, manageability $=.66$ and comprehensibility $=.75$ ). The items could be answered on a sevenpoint rating scale ranging from $1=$ "does not apply at all" to 7 $=$ "applies fully". For further calculations, a total score and the 
mean values per sub-scale can be determined. The scales ranging from 0 to 7 points, and it can be assumed that higher values indicate a stronger S-SoC.

Emotional and Social Loneliness. Emotional and social loneliness was measured by means of the six-item De Jong Gierveld loneliness scale (de Jong Gierveld \& van Tilburg, 2006). This is a reliable and valid measurement instrument for overall, emotional, and social loneliness suitable for large surveys. Three items measure social loneliness (e.g., "There are many people I can trust completely") and three items emotional loneliness ("I miss having people around"). For this sample, Cronbach's alpha was 0.67 for emotional loneliness and 0.86 for social loneliness. A 4-point rating scale: "strongly agree", "agree", "disagree", and "strongly disagree" was offered, the emotional and social loneliness scales ranging from 0 to $3(0$ $=$ not emotionally $/$ not socially lonely, $1-3=$ emotionally $/$ socially lonely) and the general loneliness scale from 0 to 6 $(0-1=$ not lonely, $2-4=$ moderately lonely, $5-6$ severely lonely). Further, as a rough, quantitative indicator for social support, data on the number of friend-like relationships at the CUAS were collected.

Sociodemographic and study-related variables. Sex and age were included as sociodemographic variables. Field of study as defined within CUAS (Health Sciences and Social Work, Management, Engineering and IT, Civil Engineering \& Architecture), intended degree (Bachelor or Master) and mode of study (full-time or part-time student) were chosen as studyrelated variables.

\section{Statistical Analysis}

Several steps for data analysis were performed using IBM SPSS Statistics 25 (IBM Corporation, Armonk, NY, USA) and R 3.6.2 (R Core Team, 2020) with the R-package gRim 2020.

Shapiro-Wilk tests were used to check the normality assumption for social and emotional loneliness, comprehensibility, meaningfulness and manageability, number of friend-like relationships and age. All of them were non-normal. Therefore rank-based tests were used for bivariate analyses and, for the graphical model, the before mentioned variables were ranktransformed.

\section{Bivariate Analysis}

First, bivariate analyses were carried out by computing Spearman correlations among all loneliness and S-SoC subscales, age and friend-like relationships. The five sub-scales (emotional and social loneliness, comprehensibility, meaningfulness and manageability) were tested with regard to potential differences between sub groups of the variables sex, field of study, mode of study and study degree using Kruskal-
Wallis H-tests. For these tests, $p$-values below $\alpha=5 \%$ were considered statistically significant.

\section{Graphical Models}

Exploring the structural relationships between loneliness, SSoC, and a set of control variables beyond bivariate analyses was of interest. When dealing with a substantially large set of variables, as in this case, the overwhelming number of possible models necessitates a selection strategy. Here, graphical models (Højsgaard et al., 2012) were chosen, which allow for a flexible and efficient model selection, eliminate the need for several different models, and have a number of favorable characteristics to facilitate the interpretation of the arising multivariate dependencies. The name graphical models derive from the mathematical concept of graphs, which are a set of vertices (or nodes) representing variables in this case, with edges connecting the nodes and showing the relationships between them. In statistical models formulated this way, findings from the graph theory can be employed to interpret the relationships between variables, such asecomposability and conditional independence (Edwards, 2000).

To model the data, undirected homogeneous mixedinteraction models (Højsgaard et al., 2012) were used, which are flexible enough to handle continuous and categorical variables yet are feasible for the obtained data due to certain restrictions. Dependencies among metric variables are modeled using a concentration matrix containing partial correlations (i.e., correlations without any effects on the remaining variables), whereas log-linear models are used for associations between categorical variables. Relationships between mixed pairs of categorical and continuous variables are quantified using homogeneous conditional Gaussian densities where the covariance structure is constant, but means vary between levels of the categorical variables.

Nine variables were modeled, which were selected based on the bivariate tests described above: All sub-scales of the SSoC (comprehensibility, meaningfulness, and manageability) and loneliness (social and emotional) as well as age, the number of friend-like relationships at the CUAS, intended degree, and sex (all except nominal variables were rank-transformed). The control variables field of study and study degree were omitted since they did not show significant results in the tests. The model selection was performed backward from a saturated model, with the restriction that the resulting model must be decomposable. This means that iteratively all edges in the model were tested and, if one or more could be removed without significantly worsening the model, the optimal edge was determined and deleted. This process was repeated until no more edges could be removed. To account for inflated type-I-error rates, a distinction was made between results significant at the nominal $\alpha=5 \%$ level and at the Bonferronicorrected $\alpha_{a d j}=0.25 \%$. All analyses were conducted in the 
statistical environment R (R Core Team, 2020) using the package gRim (Højsgaard, 2020).

\section{Results}

\section{Descriptive Results}

On average, the S-SoC was $4.65(S D=0.96)$. Comprehensibility was rated with $4.39(S D=1.16)$, meaningfulness with 4.64 $(S D=0.88)$ and manageability with $4.89(S D=1.27)$.

The majority $(63.5 \%)$ did not feel generally lonely. Moderate loneliness was reported by $31.7 \%$, and $4.8 \%$ felt severely lonely. The average loneliness score was 1.36 (SD $=1.55)$. The majority did not feel emotionally $(89.6 \%)$ or socially lonely $(70.7 \%)$. However, more than a quarter (29.4\%) mentioned to feel socially lonely (11.5\% had a score of 2 , and $17.9 \%$ had a score of 3 ).

Students who stated not to be affected by loneliness had a S-SoC average score of $4.88(S D=0.90)$, students who reported moderate loneliness scored $4.26(S D=.91)$ and students with severe loneliness issues merely $3.83(S D=1.13$ ) on average. These results were found statistically significant based on the Kruskal-Wallis $H$-test $\left(\chi^{2}(2)=60.58, p<.001\right)$. Post-hoc tests revealed that the group without reported loneliness differed significantly from the groups exhibiting moderate to severe loneliness, resulting in students with moderate or severe loneliness having lower S-SoC scores than not lonely participants.

\section{Differences between Emotional/Social Loneliness and Sub-Scales of S-SoC, Sex, Mode of Study, Age, Field of Study, Intended Degree and Number of Friend-like Relationships at CUAS}

Part-time students felt more socially lonely than full-time students $\left(\chi^{2}(1)=5.02, p=.025\right)$ and had a lower average score concerning the comprehensibility $\left(\chi^{2}(1)=6.92, p=.009\right)$. Further, male students experienced university-centered processes more comprehensible and predictable than female students $\left(\chi^{2}(1)=5.71, p=.017\right)$. There were no statistically significant differences regarding intended degrees and field of study (see Table 1).

\section{Correlation between Social/ Emotional Loneliness, Dimensions of S-SoC, Number of Friend-like Relationships and Age}

The reported correlations were found statistically significant by using Spearman rank-order correlations and can be seen in Table 2. Emotional and social loneliness were both negatively correlated with all three dimensions of the S-SoC and positively correlated with each other.
Social loneliness was negatively correlated with the number of friend-like relationships and positively correlated with age. Manageability, meaningfulness and comprehensibility were positively correlated with the number of friend-like relationships.

\section{Results from the Graphical Model}

The graphical model was designed using a backward selection from the saturated model of all variables (in each iteration, edges with $p<.05$ were deleted). Cases with missing values had to be excluded list-wise, which leads to a reduced sample size of $N=508$ for these analyses. Tests of all the edges that remained in the final model are displayed in Panel A of Table 3, and the graph is shown in Panel B.

Note Panel B: White nodes are continuous and gray nodes categorical variables.

As seen in the graphical model (Table 3.), manageability is negatively correlated to emotional $(r=-.182 ; p<.001)$ and social loneliness $(r=-.167 ; p<.001)$ but positively correlated to the other S-SoC subscales comprehensibility $(r=$ $.396 ; p<.001)$ and meaningfulness $(r=.322 ; p<.001)$. Comprehensibility and meaningfulness are also positively correlated $(r=.383 ; p<.001)$. Social loneliness in turn is negatively correlated to the number of friend-like relationships $(r=-.355 ; p<.001)$ and shows sex-related differences ( $p=.043$; males $M=0.98$, females $M=0.91$ ).

Aside from our main variables of interest (loneliness and $\mathrm{S}$ SoC), there are some strong associations among control variables. Sex is associated with age $(p<.001)$ and the number of friend-like relationships $(p<.001)$, where male students reported a higher average number $(M=9.99)$ than females $(M$ $=6.52$ ). Age is furthermore associated with the respective mode of study $(p<.001)$.

\section{Discussion}

Loneliness is a more and more common public health issue, and loneliness and problems regarding social integration have recently also been discussed in the context of students' health (Diehl et al., 2018; Stadtfeld et al., 2019) and can be seen as a challenge. An active approach to handling this challenge as early as when students are in education programs is crucial. The uniqueness of this study can be seen in the combined examination of a stressor and the use of a resourceorientated approach. This approach contrasts with previous studies that have more often taken a pathogenic perspective (i.e., a risk factor approach). The present study makes an innovative contribution to exploring the relation between loneliness and the S-SoC among students in a university setting. Furthermore, a graphical model was generated to show the structural relationships among the variables. 


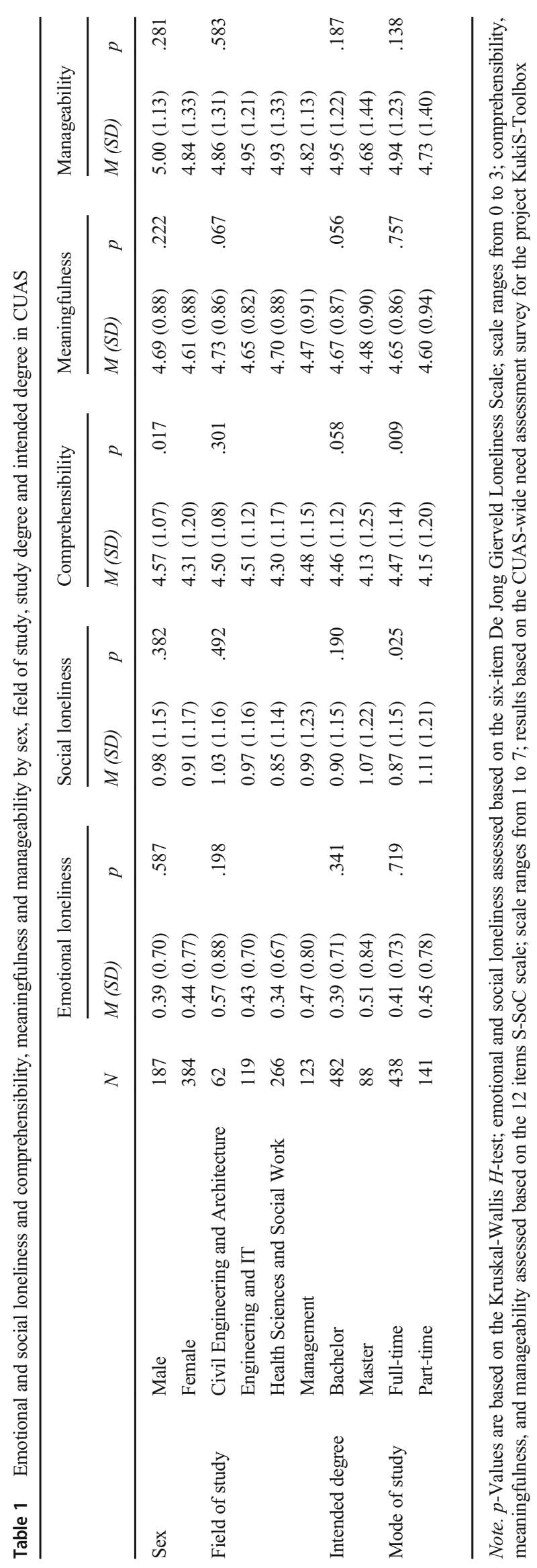


Table 2 Spearman correlations between emotional and social loneliness, dimensions of S-SoC, number friend-like relationships and age

\begin{tabular}{|c|c|c|c|c|c|c|c|c|}
\hline & Variable & (1) & (2) & (3) & (4) & (5) & (6) & (7) \\
\hline (1) & Emotional loneliness & 1 & & & & & & \\
\hline (2) & Social loneliness & $.264 * *$ & 1 & & & & & \\
\hline (3) & Comprehensibility & $-.233 * *$ & $-.225 * *$ & 1 & & & & \\
\hline (4) & Meaningfulness & $-.265 * *$ & $-.240 * *$ & $.604 * *$ & 1 & & & \\
\hline (5) & Manageability & $-.300 * *$ & $-.314 * *$ & $.621 * *$ & $.571 * *$ & 1 & & \\
\hline (6) & $\begin{array}{l}\text { Number of friend-like } \\
\text { relationships }\end{array}$ & -.072 & $-.392 * *$ & $.144 * *$ & $.088 *$ & $.196 * *$ & 1 & \\
\hline (7) & Age & -.016 & $.094 *$ & -.019 & $.090 *$ & -.032 & $-.098 *$ & 1 \\
\hline
\end{tabular}

Note. $* p<.05 * * p<.01$
Loneliness was prevalent in university students, with $31.7 \%$ feeling moderately lonely and $4.8 \%$ severely lonely. Diehl et al. (2018), who analyzed the prevalence of loneliness among German university students, obtained similar results. This study demonstrates that social loneliness is more common than emotional loneliness among CUAS students. Concerning the definition of emotional and social loneliness, students can have one or two close "buddies" instead of a broader social group. An explanation for this target group can be found in individuals' competition to achieve higher grades or to have the possibility to enter to limited advanced study opportunities and also of their perceived labor market competition (Jackson \& Tomlinson, 2020; Moran et al., 2011). Moreover, male students reported more frequently to be socially lonely than females. An explanation for gender differences may assume that women shy away from competition more often than men (Buser et al., 2014).

Examining the connection between general loneliness and S-SoC showed that a high S-SoC was associated with lower loneliness levels. Chu et al. (2016) reported an association between social support, a lower feeling of isolation and a stronger SoC among university students in China. A high SoC, in general, strengthens health and is linked to effective coping with perceived stressors (Campagne, 2019). Therefore, students with a high S-SoC might have effective coping strategies (e.g., social support) to cope with feelings of loneliness.

Female students reported a lower number of friend-like relationships than their male colleagues. The assumption is that women have more profound and more qualitative friendships than men, so female students reported fewer friend-like relationships and felt less socially lonely than men. According to this, a purely quantitative assessment of friend-like relationships does not indicate if a person feels to be in good hands. Nevertheless, looking at quantitative (number of friend-like relationships) and qualitative responses can reveal whether or not a person feels lonely in their friendships. An explanation may be found in the different descriptions of friendship. The friendship between men can be described as instrumental, action-oriented rather than person-oriented, whereas women's friendships involve more support, emotional disclosure and complexity (Morrison \&
Cooper-Thomas, 2017). In this context, many other aspects like composition and functioning of the network are worth to mention (de Jong Gierveld et al., 2018).

Furthermore, part-time students felt more socially lonely and had a lower average score concerning comprehensibility, which may be caused by the fact that part-time students are often affected by different stressors. Therefore, the fulfillment of work-related, family-related and study-related commitments or inadequate self-organization, disorientation within the university, academic performance pressure might be stressors. Furthermore, less time to fulfill study-related tasks and often little social support from the employer can be named as potential stressors of part-time students (Brunner \& Kada, 2011; Sahari et al., 2013).

As seen in the graph, manageability is a pivotal point in this model, as it is strongly connected to the other S-SoC scales and inversely proportional to both measures of loneliness. A possible interpretation could be that students activate appropriate resources to fulfill study-related demands, which corresponds to low social and emotional loneliness. Partial correlations are lower than the reported bivariate values because any effects of other variables were removed in the latter. However, these partial correlations let some previously significant correlations vanish and reveal a bigger picture where manageability is the key element connecting social and emotional loneliness. An explanation for this may be found in the statement that manageability means not only the feeling of having own resources and competencies it is also the belief that other people or a higher power can help overcome difficulties (Bengel et al., 2009). Therefore, within the manageability, social support might be essential to cope effectively with loneliness as a stressor. This leads to the assumption that within S-SoC, manageability is an essential factor to cope with loneliness. It also brings up the critical question to what extent manageability and social support are distinct constructs or perhaps have strong analogous characteristics. In several research studies, theoretical constructs, such as self-concepts and self-efficacy, overlap, and researchers often struggle to decipher the distinctive characteristics (Bong \& Skaalvik, 2003; Peiffer et al., 2020). 
Table 3 Edges in the Graphical Model with Tests

\begin{tabular}{|c|c|c|c|c|c|c|}
\hline Connected Variables & & $\chi^{2}$ & $d f$ & $p$-value & $\triangle A I C$ & \\
\hline Age & Mode of study & 91.48 & 2 & $<.001$ & 87.48 & ** \\
\hline Manageability & Comprehensibility & 48.31 & 1 & $<.001$ & 46.31 & $* *$ \\
\hline Comprehensibility & Meaningfulness & 41.08 & 1 & $<.001$ & 39.08 & $* *$ \\
\hline Social loneliness & No. friend-like relationships & 36.00 & 1 & $<.001$ & 34.00 & $* *$ \\
\hline Manageability & Meaningfulness & 30.71 & 1 & $<.001$ & 28.71 & ** \\
\hline Sex & Age & 18.79 & 2 & $<.001$ & 14.79 & $* *$ \\
\hline Manageability & Emotional loneliness & 15.13 & 1 & $<.001$ & 13.13 & ** \\
\hline Sex & No. friend-like relationships & 14.46 & 1 & $<.001$ & 12.46 & $* *$ \\
\hline Manageability & Social loneliness & 12.74 & 1 & $<.001$ & 10.74 & ** \\
\hline Social loneliness & Emotional loneliness & 8.11 & 1 & .004 & 6.11 & $*$ \\
\hline No. friend-like relationships & Age & 5.39 & 1 & .020 & 3.39 & $*$ \\
\hline Age & Meaningfulness & 5.18 & 1 & .023 & 3.18 & $*$ \\
\hline Sext & Mode of study & 8.68 & 3 & .034 & 2.68 & $*$ \\
\hline Social loneliness & Sex & 4.08 & 1 & .043 & 2.08 & $*$ \\
\hline Comprehensibility & Mode of study & 3.93 & 1 & .047 & 1.93 & $*$ \\
\hline Manageability & Age & 1.43 & 1 & .232 & -0.57 & \\
\hline Manageability & No. friend-like relationships & 0.73 & 1 & .394 & -1.27 & \\
\hline Manageability & Mode of study & 0.75 & 2 & .687 & -3.25 & \\
\hline Meaningfulness & Mode of study & 0.16 & 1 & .689 & -1.84 & \\
\hline Manageability & Sex & 0.34 & 2 & .845 & -3.66 & \\
\hline
\end{tabular}

Note. Edges are sorted by increasing $p$-values. The order of connected variables does not matter, as the model is undirect. Edges with $p>.05$ were kept to keep the models graphical and decomposable. $\triangle A I C$ : change in AIC if variable is deleted. * $p<.05, * * p<.0025$.

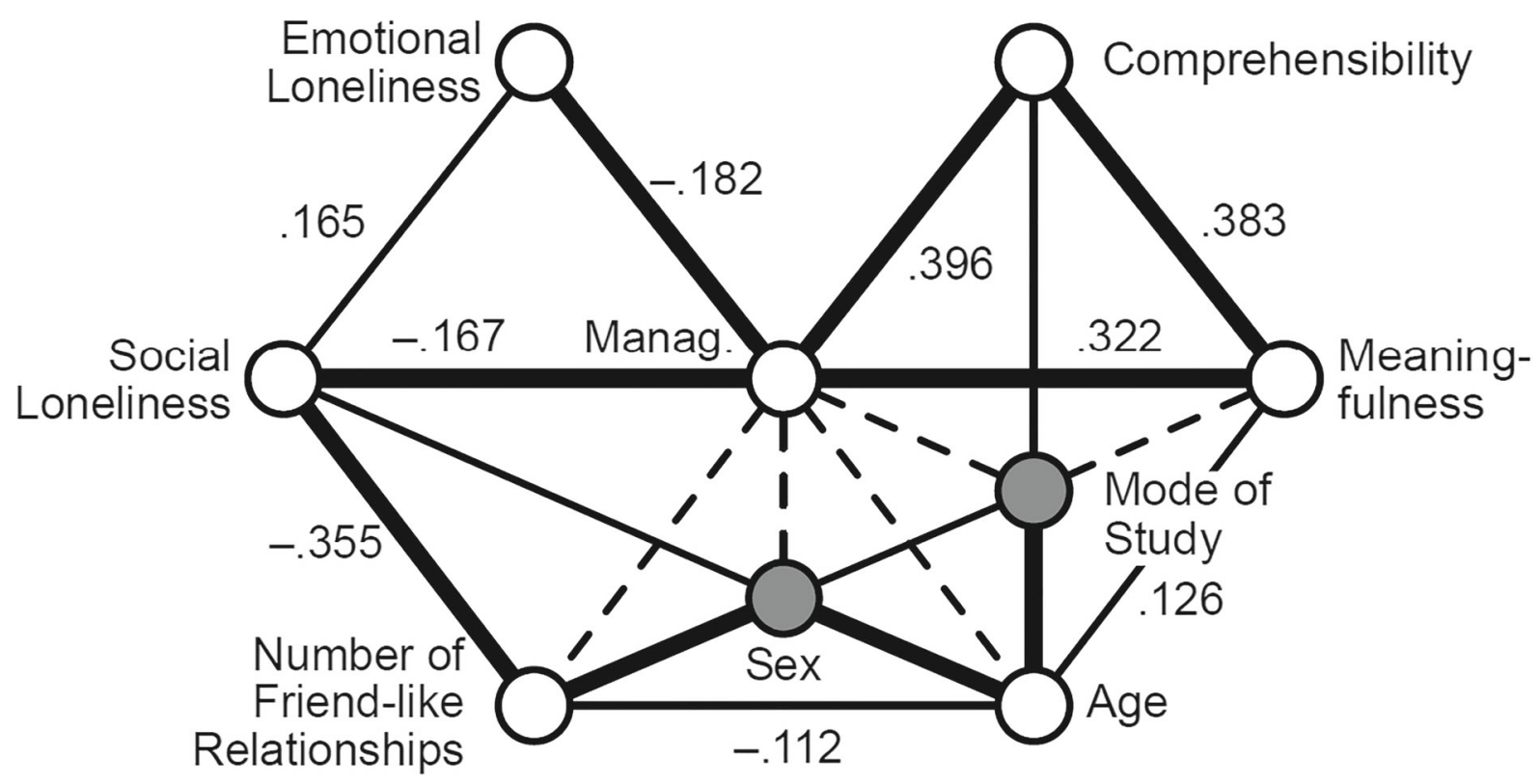

Throughout the health-related literature, sound, programmatic approaches are offered, but mostly there is only a loose reference to salutogenesis (Bauer, 2017). Furthermore, Dooris et al. (2017) point out that investigating health and well-being in the university setting should not be done without addressing health needs and problems with a salutogenic focus. Focusing on the S-SoC indicates not only changes at the individual level but also offers information for interventions at the structural level. For example, to prevent loneliness and strengthen social support and manageability, good onboarding programs for freshmen are needed to promote a strong $\mathrm{S}-\mathrm{SoC}$, social support and belonging from the beginning of the study. Furthermore, to strengthen comprehensibility, for example, transparent and structured communication about examination 
requirements for the whole university is needed. However, a holistic view on the relation between $\mathrm{SoC}$ and its' concepts of stress, coping and social support (Heiman, 2004) is needed. Thus, it might be useful to take measures against loneliness and intervene on the behavioral dimension to promote a positive change in the response against stressors (Super et al., 2016)

The university setting could be an appropriate learning environment for promoting social support and enhancing SoC. Respecting others, transferring responsibility, improving transparent communication or values (e.g., friendliness, humor, tolerance) within work or learning interactions maintained and improved SOC (Mayer \& Boness, 2011). So, within the university setting, a conglomerate of different interventions focusing on social and personal skills training and awareness raising might be helpful.

Peer approaches might be successful in promoting social and personal skills and raise awareness of the topic. For example, peer-mentoring programs provide social connections with other students and thus positively affect the sense of belonging or the development of social skills. Additionally, such programs benefit the mentee and the mentor (Glaser et al., 2006). Herrmann-Werner et al. (2018) found out that a Tandem Program reduced perceived stress and improved the ability to work in a team among medical students. Currently, the focus is still on short-term behavioral interventions and projects for students (Hartmann et al., 2016). However, health-promoting interventions should focus on individual and structural levels and continuously be offered throughout the study duration. This commitment can guarantee sustainability in working for the students' health and improving the study situation. Good health-promoting onboarding programs strengthening the dimensions of S-SoC, promoting group support and the sense of belonging are needed. Since 2015 a best practice project called "Healthy Study Start" (Mir \& Gebhard, 2015) was implemented in different study programs at the CUAS. Within this project, peer approaches to promote the sense of belonging in first term students and the provision of resources are central. Moreover, in March 2019, another project named KukiS-Toolbox (a German project called "Kompetent und kohärent im Studium-Toolbox", a project to strengthen personal and social competencies among students) started. It focuses on strengthening the dimensions of S-SoC, promoting group support and the sense of belonging by developing learning and teaching materials, participating full-time and part-time students.

However, promoting social and personal skills within the university follows the key principles for action of the Okanagan Charter (2015). Such a promotion also sends a signal for students' health management (Techniker Krankenkasse, 2019). Moreover, social and personal skills training, including peer approaches, may help develop collaborative work skills, leading to better employability.

\section{Limitations}

The study's exploratory nature revealed the described structural relationships between the variables, yet these effects need to be confirmed in future studies. Furthermore, the study did not consider the salutogenic model holistically but used a free exploration of some aspects. As well, other stressors and GRRs were not considered. Furthermore, the number of friend-like relationships can only be seen as a rough, insufficient indicator for measuring social support.

Although the sample size was considerably large, more data would permit a more comprehensive analysis, as some statistically not significant control variables had to be left out of the graphical model. Furthermore, with more respondents, the constructs could be investigated with models for categorical indicator items (e.g., Item Response Theory, Rasch models).

Due to the population sampled from, some discovered effects might be attributable to this specific setting (CUAS students).

Since all variables were self-reported, the authors cannot rule out a social desirability bias. Finally, due to the crosssectional design and the undirected model, these results do not allow conclusions about causality.

\section{Further Research}

Future research should investigate hypotheses derived from these findings. Also, research analyzing loneliness and the S-SoC with health-related outcomes in the university context is needed. Moreover, the necessity of evaluating the quality of social support could be an aim within further research.

Furthermore, considering other coping strategies to overcome loneliness and other stressors and using a holistic approach of the salutogenic model are needed. However, further empirical research is needed to clarify the extent to which manageability and social support are distinct constructs. Further studies should use comprehensive, valid instruments to have a more differentiated view on the construct of social support.

Moreover, clearly defined and documented interventions, as well as high-quality trials, are required. The interplay between the S-SoC dimensions and their relationship to other health-related concepts needs more investigation. Prospectively tailored interventions to promote S-SoC, especially within an educational setting, are needed. All in all, further empirical research is needed to underline the importance of a strong S-SoC to prevent loneliness among university students.

Code Availability Not applicable.

Funding Open access funding provided by Carinthia University of Applied Sciences (CUAS). 
Data Availability Not applicable.

\section{Declarations}

Conflict of Interest The authors declare that they have no conflict of interest.

Open Access This article is licensed under a Creative Commons Attribution 4.0 International License, which permits use, sharing, adaptation, distribution and reproduction in any medium or format, as long as you give appropriate credit to the original author(s) and the source, provide a link to the Creative Commons licence, and indicate if changes were made. The images or other third party material in this article are included in the article's Creative Commons licence, unless indicated otherwise in a credit line to the material. If material is not included in the article's Creative Commons licence and your intended use is not permitted by statutory regulation or exceeds the permitted use, you will need to obtain permission directly from the copyright holder. To view a copy of this licence, visit http://creativecommons.org/licenses/by/4.0/.

\section{References}

Aalbers, G., McNally, R. J., Heeren, A., de Wit, S., \& Fried, E. I. (2019). Social media and depression symptoms: A network perspective. Journal of Experimental Psychology. General, 148(8), 14541462. https://doi.org/10.1037/xge0000528.

Antonovsky, A. (1979). Health, stress and coping: New perspectives of mental and physical well-being. Jossey-Bass.

Bauer, G. F. (2017). The application of Salutogenesis in everyday settings. In M. B. Mittelmark, S. Sagy, M. Eriksson, G. F. Bauer, J. M. Pelikan, B. Lindström, \& G. A. Espnes (Eds.), The Handbook of Salutogenesis (pp. 153-158). Springer International Publishing.

Bengel, J., Strittmatter, R., \& Willmann, H. (2009). Was erhält Menschen gesund? Antonovskys Modell der Salutogenese - Diskussionsstand und Stellenwert [WHAT KEEPS PEOPLE HEALTHY? Antonovsky's model of salutogenesis - state of discussion and significance] (Erw. Neuaufl.). Forschung und Praxis der Gesundheitsförderung: Vol. 6. BZgA. http://www.bzga.de/ infomaterialien/forschung-und-praxis-der-gesundheitsfoerderung/ band-06-was-erhaelt-menschen-gesund-antonovskys-modell-dersalutogenese/?uid=73b3d0d3bacf00d680c541859efb46f3 https:// doi.org/10.4126/38m-002470156. Accessed 19 Dec 2020.

Bong, M., \& Skaalvik, E. M. (2003). Academic self-concept and selfefficacy: How different are they really? Educational Psychology Review, 15(1), 1-40. https://doi.org/10.1023/A:1021302408382.

Bruffaerts, R., Mortier, P., Kiekens, G., Auerbach, R. P., Cuijpers, P., Demyttenaere, K., Green, J. G., Nock, M. K., \& Kessler, R. C. (2018). Mental health problems in college freshmen: Prevalence and academic functioning. Journal of Affective Disorders, 225, 97-103. https://doi.org/10.1016/j.jad.2017.07.044.

Brunner, E., Maier, M., Gritsch, A., \& Jenull, B. (2009). Die Universität Ein kohärentes Setting? [The university - A coherent setting?]. Prävention Und Gesundheitsförderung, 4(1), 66-70. https://doi. org/10.1007/s11553-008-0149-6.

Brunner, E., \& Kada, O. (2011). Berufsbegleitend Studieren - Ein Gesundheitsrisiko? Konzeption und umsetzung einer Lehrveranstaltung zum Thema "Gesundheitsförderung [Part-time study - a health risk? Conception and implementation of a study course on "Health Promotion"]. In Lernwelten (Ed.), Didaktik und Bildungsverständnis: Pädagogik in der Pflege- und Therapieausbildung (pp. 275-284). Hungen: hpsmedia.
Buser, T., Niederle, M., \& Oosterbeek, H. (2014). Gender. Competitiveness, and Career Choices The Quarterly Journal of Economics, 129(3), 1409-1447. https://doi.org/10.1093/qje/qju009.

Campagne, D. M. (2019). Stress and perceived social isolation (loneliness). Archives of Gerontology and Geriatrics, 82, 192-199. https:// doi.org/10.1016/j.archger.2019.02.007.

Chu, J. J., Khan, M. H., Jahn, H. J., \& Kraemer, A. (2016). Sense of coherence and associated factors among university students in China: Cross-sectional evidence. BMC Public Health, 16, 336. https://doi.org/10.1186/s12889-016-3003-3.

Diehl, K., Jansen, C., Ishchanova, K., \& Hilger-Kolb, J. (2018). Loneliness at universities: Determinants of emotional and social loneliness among students. International Journal of Environmental Research and Public Health, 15(9). https://doi.org/10.3390/ ijerph15091865.

Dooris, M., Doherty, S., \& Orme, J. (2017). The application of Salutogenesis in universities. In M. B. Mittelmark, S. Sagy, M. Eriksson, G. F. Bauer, J. M. Pelikan, B. Lindström, \& G. A. Espnes (Eds.), The Handbook of Salutogenesis (237-236). Springer International Publishing.

Edwards, D. (2000). Introduction to graphical modelling. Springer International Publishing.

Eissler, C., Sailer, M., Walter, S., \& Jerg-Bretzke, L. (2020). Psychische Gesundheit und Belastung bei Studierenden [Mental health and strain in students]. Prävention Und Gesundheitsförderung, 15(3), 242-249. https://doi.org/10.1007/s11553-019-00746-z.

Eriksson, M., \& Lindström, B. (2006). Antonovsky's sense of coherence scale and the relation with health: A systematic review. Journal of Epidemiology and Community Health, 60(5), 376-381. https://doi. org/10.1136/jech.2005.041616.

Faltermaier, T. (2018). Salutogenese und Ressourcenorientierung [Salutogenesis and resource orientation]. In C.-W. Kohlmann, C. Salewski, \& M. A. Wirtz (Eds.), Psychologie in der Gesundheitsförderung [Psychology of Health Promotion] (pp. 8598). Hogrefe.

Feldt, T., Leskinen, E., Kinnunen, U., \& Ruoppila, I. (2003). The stability of sense of coherence: Comparing two age groups in a 5-year follow-up study. Personality and Individual Differences, 35(5), 11511165. https://doi.org/10.1016/S0191-8869(02)00325-2.

Glaser, N., Hall, R., \& Halperin, S. (2006). Students supporting students: The effects of peer mentoring on the experiences of first year university students. Journal of the Australia and New Zealand Student Services, 27, 4-19.

Gräser, S. (2003). Hochschule und Gesundheit: Salutogenese am Arbeitsplatz Universität [university and health: Salutogenesis at the workplace university]. Pabst Science Publishers.

Griffin, S. C., Williams, A. B., Ravyts, S. G., Mladen, S. N., \& Rybarczyk, B. D. (2020). Loneliness and sleep: A systematic review and meta-analysis. Health Psychology Open, 7(1), 2055102920913235. https://doi.org/10.1177/2055102920913235.

Hartmann, T., Baumgarten, K., Hildebrand, C., \& Sonntag, U. (2016). Gesundheitsfördernde Hochschulen. Das Präventionsgesetz eröffnet neue Perspektiven für die akademische Lebenswelt [health promoting universities. The prevention act opens up newperspectives for academia]. Prävention Und Gesundheitsförderung, 11(4), 243-250. https://doi.org/10.1007/s11553-016-0564-z.

Hayley, A. C., Downey, L. A., Stough, C., Sivertsen, B., Knapstad, M., \& Øverland, S. (2017). Social and emotional loneliness and selfreported difficulty initiating and maintaining sleep (DIMS) in a sample of Norwegian university students. Scandinavian Journal of Psychology, 58(1), 91-99. https://doi.org/10.1111/sjop.12343.

Heiman, T. (2004). Examination of the salutogenic model, support resources, coping style, and stressors among Israeli university students. The Journal of Psychology, 138(6), 505-520. https://doi. org/10.3200/JRLP.138.6.505-520. 
Herrmann-Werner, A., Junne, F., Stuber, F., Huhn, D., Nikendei, C., Seifried-Dübon, T., Zipfel, S., \& Erschens, R. (2018). Reducing stress and promoting social integration of international medical students through a tandem program: Results of a prospective-program evaluation. International Journal of Environmental Research and Public Health, 15(9). https://doi.org/10.3390/ijerph15091959.

Højsgaard, S., Edwards, D., \& Lauritzen, S. (2012). Graphical models with $R$. Springer International Publishing.

Højsgaard, S. (2020). gRim: Graphical interaction models.: R package version 0.2.1. https://www.r-project.org/. Accessed 13 May 2020.

Holt-Lunstand, J. (2017). Friendship and health. In M. Hojjat \& A. Moyer (Eds.), The Psychology of Friendship (pp. 233-249). Oxford University Press.

Ibrahim, A. K., Kelly, S. J., Adams, C. E., \& Glazebrook, C. (2013). A systematic review of studies of depression prevalence in university students. Journal of Psychiatric Research, 47(3), 391-400. https:// doi.org/10.1016/j.jpsychires.2012.11.015.

Idan, O., Eriksson, M., \& Al-Yagon, M. (2017). The salutogenic model: The role of generalized resistance resources. In M. B. Mittelmark, S. Sagy, M. Eriksson, G. F. Bauer, J. M. Pelikan, B. Lindström, \& G. A. Espnes (Eds.), The Handbook of Salutogenesis (pp. 57-69). Springer International Publishing.

Jackson, D., \& Tomlinson, M. (2020). Investigating the relationship between career planning, proactivity and employability perceptions among higher education students in uncertain labour market conditions. Higher Education, 80(3), 435-455. https://doi.org/10.1007/ s10734-019-00490-5.

de Jong Gierveld, J., \& van Tilburg, T. (2006). A 6-item scale for overall, emotional, and social loneliness. Research on Aging, 28(5), 582598. https://doi.org/10.1177/0164027506289723.

de Jong Gierveld, J., \& van Tilburg, T. (2010). The De Jong Gierveld short scales for emotional and social loneliness: Tested on data from 7 countries in the UN generations and gender surveys. European Journal of Ageing, 7(2), 121-130. https://doi.org/10.1007/s10433010-0144-6.

de Jong Gierveld, J., van Tilburg, T. G., \& Dykstra, P. A. (2018). New ways of theorizing and conducting research in the field of loneliness and social isolation. In A. L. Vangelisti \& D. Perlman (Eds.), The Cambridge handbook of personal relationships (pp. 391-404). Cambridge University Press. https://doi.org/10.1017/ 9781316417867.031

Koelen, M., Eriksson, M., \& Cattan, M. (2017). Older people, sense of coherence and community. In M. B. Mittelmark, S. Sagy, M. Eriksson, G. F. Bauer, J. M. Pelikan, B. Lindström, \& G. A. Espnes (Eds.), The Handbook of Salutogenesis (pp. 137-152). Springer International Publishing.

Lee, C.-Y. S., \& Goldstein, S. E. (2016). Loneliness, stress, and social support in young adulthood: Does the source of support matter? Journal of Youth and Adolescence, 45(3), 568-580. https://doi.org/ 10.1007/s10964-015-0395-9.

Leigh-Hunt, N., Bagguley, D., Bash, K., Turner, V., Turnbull, S., Valtorta, N., \& Caan, W. (2017). An overview of systematic reviews on the public health consequences of social isolation and loneliness. Public Health, 152, 157-171. https://doi.org/10.1016/j.puhe.2017. 07.035 .

Lundberg, O., \& Toivanen, S. (2019). Sense of coherence and social structure. In J. O. Nriagu (Ed.), Encyclopedia of Environmental Health (2nd ed., updated version, pp. 704-709). Elsevier. https:// doi.org/10.1016/B978-0-12-409548-9.11754-3.

Maes, M., Qualter, P., Vanhalst, J., van den Noortgate, W., \& Goossens, L. (2019). Gender differences in loneliness across the lifespan: A meta-analysis. European Journal of Personality, 33(6), 642-654. https://doi.org/10.1002/per.2220.

Matthews, T., Danese, A., Caspi, A., Fisher, H. L., Goldman-Mellor, S., Kepa, A., Moffitt, T. E., Odgers, C. L., \& Arseneault, L. (2019). Lonely young adults in modern Britain: Findings from an epidemiological cohort study. Psychological Medicine, 49(2), 268-277. https://doi.org/10.1017/S0033291718000788.

Mayer, C.-H., \& Boness, C. (2011). Interventions to promoting sense of coherence and transcultural competences in educational contexts. International Review of Psychiatry (Abingdon, England), 23(6), 516-524. https://doi.org/10.3109/09540261.2011.637906.

McIntyre, J. C., Worsley, J., Corcoran, R., Harrison Woods, P., \& Bentall, R. P. (2018). Academic and non-academic predictors of student psychological distress: The role of social identity and loneliness. Journal of Mental Health (Abingdon, England), 27(3), 230239. https://doi.org/10.1080/09638237.2018.1437608.

Mir, E., \& Gebhard, D. (2015). Gesunder start ins Studium (- reloaded): Gesundheitsförderung für Erstsemestrige: Vom Pilotprojekt zur curricularen Verankerung [Healthy study start (-reloaded): Health promotion for first term students: From pilot project to integral part of curriculum.]. Pädagogik der Gesundheitsberufe (2), 61-66.

Mittelmark, M. B., \& Bauer, G. F. (2017). The meanings of Salutogenesis. In M. B. Mittelmark, S. Sagy, M. Eriksson, G. F. Bauer, J. M. Pelikan, B. Lindström, \& G. A. Espnes (Eds.), The Handbook of Salutogenesis (pp. 7-14). Springer International Publishing.

Moran, M., Boyce, R. A., \& Nissen, L. (2011). Competion the new collaboration? Employing inter-team competitiveness to motivate health students to learn together. In S. Kitto, J. Chesters, J. Thistlethwaite, \& S. Reeves (Eds.), Health care issues, costs and access. Sociology of interprofessional health care practice: Critical reflections and concrete solutions (pp. 155-168). Nova Science Publishers.

Morrison, R. L., \& Cooper-Thomas, H. D. (2017). Friendship among coworkers. In M. Hojjat \& A. Moyer (Eds.), The Psychology of Friendship (pp. 123-140). Oxford University Press.

Mushtaq, R., Shoib, S., Shah, T., \& Mushtaq, S. (2014). Relationship between loneliness, psychiatric disorders and physical health? A review on the psychological aspects of loneliness. Journal of Clinical and Diagnostic Research: JCDR, 8(9), WE01-WE04. https://doi.org/10.7860/JCDR/2014/10077.4828.

Okanagan Charter. (2015). Okanagan Charter. An international charter for health promoting universities \& colleges. https:/open.library. ubc.ca/cIRcle/collections/53926/items/1.0132754. Accessed 13 Apr 2020.

Peiffer, H., Ellwart, T., \& Preckel, F. (2020). Ability self-concept and self-efficacy in higher education: An empirical differentiation based on their factorial structure. PLoS One, 15(7), e0234604. https://doi. org/10.1371/journal.pone.0234604.

Perlman, D., \& Peplau, A. (1981). Toward a social psychology of loneliness. In S. Duck \& R. Gilmour (Eds.), Personal Relationships in Disorder (pp. 31-55). Academic Press.

Petitte, T., Mallow, J., Barnes, E., Petrone, A., Barr, T., \& Theeke, L. (2015). A systematic review of loneliness and common chronic physical conditions in adults. The Open Psychology Journal, 8(Suppl 2), 113-132. https://doi.org/10.2174/ 1874350101508010113.

Qualter, P., Vanhalst, J., Harris, R., van Roekel, E., Lodder, G., Bangee, M., Maes, M., \& Verhagen, M. (2015). Loneliness across the life span. Perspectives on Psychological Science: A Journal of the Association for Psychological Science, 10(2), 250-264. https://doi. org/10.1177/1745691615568999.

R Core Team. (2020). R: A language and environment for statistical computing. https://www.R-project.org/. Accessed 13 May 2020.

Richard, A., Rohrmann, S., Vandeleur, C. L., Schmid, M., Barth, J., \& Eichholzer, M. (2017). Loneliness is adversely associated with physical and mental health and lifestyle factors: Results from a Swiss national survey. PLoS One, 12(7), e0181442. https://doi.org/ 10.1371/journal.pone.0181442.

Sahari, S. H., Yusup, M. Y., Affidah, M., \& Aiza, J. (2013). Exploring working environment as a stressor for adult students. Procedia - 
Social and Behavioral Sciences, 101, 564-574. https://oi.org/10. 1016/j.sbspro.2013.07.229.

Saldarriaga, L. M., Bukowski, W. M., \& Greco, C. (2015). Friendship and happiness: A bidirectional dynamic process. In M. Demir (Ed.), Friendship and Happiness (pp. 59-78). Springer Netherlands.

Schinka, K. C., van Dulmen, M. H. M., Bossarte, R., \& Swahn, M. (2012). Association between loneliness and suicidality during middle childhood and adolescence: Longitudinal effects and the role of demographic characteristics. The Journal of Psychology, 146(1-2), 105-118. https://doi.org/10.1080/00223980.2011.584084.

Shankland, R., Kotsou, I., Vallet, F., Bouteyre, E., Dantzer, C., \& Leys, C. (2019). Burnout in university students: The mediating role of sense of coherence on the relationship between daily hassles and burnout. Higher Education, 78(1), 91-113. https://doi.org/10. 1007/s10734-018-0332-4.

Shovestul, B., Han, J., Germine, L., \& Dodell-Feder, D. (2020). Risk factors for loneliness: The high relative importance of age versus other factors. PLoS One, 15(2), e229087. https://doi.org/10.1371/ journal.pone.0229087.

Stadtfeld, C., Vörös, A., Elmer, T., Boda, Z., \& Raabe, I. J. (2019). Integration in emerging social networks explains academic failure and success. Proceedings of the National Academy of Sciences of the United States of America, 116(3), 792-797. https://doi.org/10.1073/ pnas. 1811388115 .

Super, S., Wagemakers, M. A. E., Picavet, H. S. J., Verkooijen, K. T., \& Koelen, M. A. (2016). Strengthening sense of coherence: Opportunities for theory building in health promotion. Health Promotion International, 31(4), 869-878. https://doi.org/10.1093/ heapro/dav071.

Techniker Krankenkasse (Ed.). (2019). SGM - Studentisches Gesundheitsmanagement Handlungsempfehlung zu Theorie und
Praxis. https://www.tk.de/resource/blob/2066932/ 0b63ccecb20d775c244d57ed267a322d/handlungsempfehlungzum-studentischen-gesundheitsmanagement-data.pdf. Accessed 13 Apr 2020.

Tzouvara, V., Papadopoulos, C., \& Randhawa, G. (2015). A narrative review of the theoretical foundations of loneliness. British Journal of Community Nursing, 20(7), 329-334. https://doi.org/10.12968/ bjen.2015.20.7.329.

Victor, C. R., \& Yang, K. (2012). The prevalence of loneliness among adults: A case study of the United Kingdom. The Journal of Psychology, 146(1-2), 85-104. https://doi.org/10.1080/00223980. 2011.613875.

Weiss, R. S. (1973). Loneliness: The experience of emotional and social isolation. MIT Press.

Wrzus, C., Hänel, M., Wagner, J., \& Neyer, F. J. (2013). Social network changes and life events across the life span: A meta-analysis. Psychological Bulletin, 139(1), 53-80. https://doi.org/10.1037/ a0028601.

Wrzus, C., Zimmermann, J., Mund, M., \& Neyer, F. J. (2017). Friendships in young and middle adulthood. In M. Hojjat \& A. Moyer (Eds.), The Psychology of Friendship (pp. 21-38). Oxford University Press. https://doi.org/10.1093/acprof:oso/ 9780190222024.003.0002.

Yanguas, J., Pinazo-Henandis, S., \& Tarazona-Santabalbina, F. J. (2018). The complexity of loneliness. Acta Bio-Medica : Atenei Parmensis, 89(2), 302-314. https://doi.org/10.23750/abm.v89i2.7404.

Publisher's Note Springer Nature remains neutral with regard to jurisdictional claims in published maps and institutional affiliations. 